Tropical Journal of Pharmaceutical Research September 2014; 13 (9): 1374-1383

ISSN: $1596-5996$ (print); 1596-9827 (electronic)

(c) Pharmacotherapy Group, Faculty of Pharmacy, University of Benin, Benin City, 300001 Nigeria.

All rights reserved.

Available online at http://www.tjpr.org

Original Research Article

http://dx.doi.org/10.4314/tjpr.v13i9.1

\title{
Optimisation of Ondansetron Orally Disintegrating Tablets Using Artificial Neural Networks
}

\author{
Buket Aksu ${ }^{1 *}$, Gizem Yegen ${ }^{2}$, Sevim Purisa ${ }^{3}$, Erdal Cevher ${ }^{2}$ and Yıldız Ozsoy ${ }^{2}$ \\ ${ }^{1}$ Santa Farma Drug Pharmaceuticals, Boruçiçeği Sokak, Şişli-Istanbul, ${ }^{2}$ Department of Pharmaceutical Technology, Faculty of \\ Pharmacy, ${ }^{3}$ Department of Biostatistics, Faculty of Medicine, Istanbul University, Istanbul, Turkey \\ *For correspondence: Email: baksu@santafarma.com.tr; Tel: +902122206400; Fax: +902122225759
}

\begin{abstract}
Purpose: To investigate the impact of critical quality attributes (CQAs) and critical process parameters (CPPs) on quality target product profile (QTPP) attributes of orally disintegrating tablet (ODT) containing ondansetron (OND) using two artificial neural network (ANN) programs.

Methods: Different amounts of two different commercial superdisintegrants commonly used in ODT formulations (Ludiflash $\AA$ and Parteck $\AA$ ) were examined as CQAs, while three different tablet-pressing forces were evaluated as CPPs for an orally disintegrating tablet (ODT) formulation. The impact of $C Q A s$, and CPPs on the target product profile (tablet hardness, friability and disintegration time) were analysed using gene expression programming (GEP) and neuro-fuzzy logic (NFL) models.

Results: NFL model defined the relations between CQAs, CPPs and QTPP, while GEP model favoured the use of an ODT formulation with suitable QTPP features which contained $4 \mathrm{mg}$ ondansetron, 21.30 $\mathrm{mg}$ Parteck $\AA$, and $119 \mathrm{mg}$ Avicel, fabricated with a compression force of 515 psi. In this regard, the tablet formulation demonstrated the required specifications.

Conclusion: ANN programs are a useful tool for research and development (R\&D) studies in the pharmaceutical industry and the use of ANNs can be beneficial in terms of raw materials, time and cost, as demonstrated for ondansetron ODT tablets.
\end{abstract}

Keywords: Ondansetron, Critical quality attributes, Critical process parameters, Quality target product profile, Gene expression programming, Neuro-fuzzy logic, Artificial neural network

Tropical Journal of Pharmaceutical Research is indexed by Science Citation Index (SciSearch), Scopus, International Pharmaceutical Abstract, Chemical Abstracts, Embase, Index Copernicus, EBSCO, African Index Medicus, JournalSeek, Journal Citation Reports/Science Edition, Directory of Open Access Journals (DOAJ), African Journal Online, Bioline International, Open-J-Gate and Pharmacy Abstracts

\section{INTRODUCTION}

The manufacture of pharmaceuticals is a complicated process from formulation to the finished product. This process involves multivariate interactions between raw materials and process conditions, which are crucial for process ability and product quality [1].

To design an experimental space for the required data, computerised systems such as artificial neural network ANN, genetic algorithms (GAs), and fuzzy logic are essential. Modelling with ANN methods has advantages over traditional modelling techniques, especially in the assessment of data that include non-linear relationships [2].

ANN methodology is very different from standard statistical analysis methods because it is based on an experimental model of the data-processing methods of a biological brain. Neural networks require less official statistical training and are capable of identifying complicated, non-linear relations between all possible interactions without dependent and independent variables or 
complicated equations, and they can use multiple training algorithms. In terms of model specification, ANNs do not require information on the data source; however, they require large training sets because they contain several weights that need to be estimated [2].

Fuzzy logic can be employed to define optimisation goals. Neuro-fuzzy logic (NFL), which incorporates the neural network (NN) in relation to its adaptive learning capability and the interpretative power of fuzzy logic, offers a powerful means of generating interpretable rules from complex and non-linear data [3]. Fuzzy logic has proven convenient, particularly when conflicting (coinciding) properties (such as fastdissolving hard tablets) are required. Recently, systems have been developed that combine fuzzy logic and neural networks 'learning' information from data to create new methodologies such as NFL and to produce more interconnected technologies. Membership functions for fuzzy sets can include any constant value from 0 to 1 . In fact, fuzzy logic allows shades of grey in addition to the black and white of conventional logic [2]. Fuzzy logic is also widely used in process control because the related reliability level associated with the membership functions for a set, which is described as IF (A) THEN (B), allows the statement of rules in plain terms.

GEP is a new search technique that evolves computer programs (mathematical expressions, decision trees, and logical expressions) [4]. A genetic algorithm program operates on the basis of the principle "survival of the fittest". In genetic programming, the individual elements that establish a population are typically symbolic expression trees. The expression trees are computer programs that have been modified to solve a specific problem and are selected based on their performance/convenience in solving the problem at hand. After repetitions, such computer program populations ideally discover new dimensions and are better adapted to certain selection environments. The desired result of the algorithm is a good solution with modifications aided by the evolution process [2].

The European Pharmacopoeia uses the term "orodispersible tablet" to refer to tablets that disperse readily in the mouth within 3 min before swallowing [5]. The use of orally disintegrating tablets (ODTs) is very advantageous for patients who have difficulty swallowing drugs like paediatric, geriatric and psychiatric patients who refuse to swallow and for patients with dysphagia
[6]. Direct compression is among the most common techniques that require the integration of superdisintegrants into the formulation to achieve the fast disintegration of tablets [7].

Formulation properties and process parameters affect the disintegration time of ODTs. To decrease the disintegration time of the tablet, it is necessary to avoid increasing the mechanical strength of ODTs. The mechanical strength of a tablet is related to its compression pressure and friability is inversely related to compression pressure. To ensure the quality of an ODT, these two properties should be properly balanced. ODTs are soft, friable, and unsuitable for packaging in conventional blisters or bottles because of their low compression pressure, It is therefore necessary to develop a strategy to increase the tablet's mechanical strength without sacrificing its porosity or requiring special unitdose packaging, which may add to the cost of handling fragile tablets $[8,9]$.

Ondansetron (OND) is a selective 5-HT3 receptor antagonist used to prevent the nausea and vomiting caused by chemotherapy, radiotherapy, and surgery [10]. In this study, OND was chosen as the model medication because of its low-dosage active ingredient and the suitability of its taste in terms of patient compliance.

In our study, using commercially available excipients for fast disintegrating oral preparations from two different companies; Parteck® ODT (Dmannitol and croscarmellose sodium) and Ludiflash $\circledast$ (mannitol, crospovidone and polyvinyl acetate), OND-containing ODT formulations were developed. Thereafter, the relationships between the formulation and process parameters (disintegrant type and amount, compression pressure) and the target product properties (tablet hardness, friability and disintegration time) and the pharmaceutically acceptable ODT formulation were determined using ANN models.

\section{EXPERIMENTAL}

\section{Materials}

OND was kindly supplied by the Nobel Drug Company (Istanbul, Turkey). Avicel PH 101 (microcrystalline cellulose NF) was from FMC Biopolymer (Brussels, Belgium), and Ludiflash ${ }^{\circledR}$ was from BASF (Germany). Parteck ${ }^{\circledR}$ was from Merck Co (Germany), and magnesium stearate was from $\mathrm{FACl}$ (Genoa, Italy). 


\section{Study design}

In this study, critical quality attributes (CQAs) (disintegrant type and amount) and critical process parameters (CPPs) (compression pressure) were considered the inputs, and quality target product profile (QTPP) properties (hardness, friability and disintegration time) were the outputs. The effects of disintegrant type, disintegrant amount and the impacts of compression pressure on the target product profile (tablet hardness, friability and disintegration time) were analyzed using GEP and NFL models.

\section{Compression of tablets using a direct compression technique}

In this study, OND tablets were prepared by a direct compression method according to the following independent variables: disintegrant type (Ludiflash $\AA$ or Parteck $\AA$ ), compression pressure $(200 / 600 / 1000$ psi), and hardness. The formulations and compression pressures used are presented in Table 1.

OND, a superdisintegrant (Parteck ${ }^{\circledR}$ or Ludiflash ${ }^{\circledR}$ ) and microcrystalline cellulose (Avicel) were mixed for $15 \mathrm{~min}$ in a cubic mixer (Erweka, Hausenstamm, Germany) to produce a uniformly mixed powder. The mixture was sieved through a $700 \mu \mathrm{m}$ sieve, lubricated with magnesium stearate and additionally mixed for 1 min in same mixer. The lubricated powder was compressed into tablets in a single tablet punch press machine (Korsch, EK-0, Germany) using three different compression pressures $(200,600$ or $1000 \mathrm{psi})$.

\section{Evaluation of ondansetron orally dispersible tablets}

\section{Pre-compression parameters}

Initially, the type and concentration of the disintegrants were varied to determine various formulations, and these formulations were analysed in terms of their suitability with compressibility. Direct compression of the tablets, flow properties such as bulk density, tapped density, Carr's (Compressibility) index and Hausner ratio [11] of the powder blends ( $F 1$ F18) were evaluated.

\section{Post-compression parameters}

All the prepared ODTs containing OND were evaluated for uniformity of weight, hardness, friability, and disintegration time.

\section{Weight variation}

Twenty randomly selected tablets were weighed individually and together in a single pan balance (Denver Instruments, USA). The mean weight and standard deviation were calculated [12].

\section{Hardness}

Tablet hardness, which is the force required to break a tablet, was measured with a tablet hardness tester (HT1, Sotax, Switzerland), and mean vale and standard deviation was calculated $(n=10)$ [13].

Table 1: Composition and compression pressure of ODT formulations

\begin{tabular}{|c|c|c|c|c|c|c|c|c|c|}
\hline \multirow{2}{*}{ Variable } & \multicolumn{9}{|c|}{ Formulation } \\
\hline & F1 & F2 & F3 & F4 & F5 & F6 & F7 & F8 & F9 \\
\hline Compressive strength (psi) & 200 & 200 & 200 & 600 & 600 & 600 & 1000 & 1000 & 1000 \\
\hline Ondansetron (mg) & 4 & 4 & 4 & 4 & 4 & 4 & 4 & 4 & 4 \\
\hline $\operatorname{Ludiflash}^{\circledR}(\mathrm{mg})$ & 20 & 60 & 100 & 20 & 60 & 100 & 20 & 60 & 100 \\
\hline Avicel (mg) & 175 & 135 & 95 & 175 & 135 & 95 & 175 & 135 & 95 \\
\hline Magnesium stearate (mg) & 1 & 1 & 1 & 1 & 1 & 1 & 1 & 1 & 1 \\
\hline \multirow[t]{2}{*}{ Total weight (mg) } & 200 & 200 & 200 & 200 & 200 & 200 & 200 & 200 & 200 \\
\hline & F10 & F11 & F12 & F13 & F14 & F15 & F16 & F17 & F18 \\
\hline Compressive strength (psi) & 200 & 200 & 200 & 600 & 600 & 600 & 1000 & 1000 & 1000 \\
\hline Ondansetron (mg) & 4 & 4 & 4 & 4 & 4 & 4 & 4 & 4 & 4 \\
\hline Parteck $^{(B)}(\mathrm{mg})$ & 20 & 60 & 100 & 20 & 60 & 100 & 20 & 60 & 100 \\
\hline Avicel (mg) & 175 & 135 & 95 & 175 & 135 & 95 & 175 & 135 & 95 \\
\hline Magnesium stearate (mg) & 1 & 1 & 1 & 1 & 1 & 1 & 1 & 1 & 1 \\
\hline Total weight (mg) & 200 & 200 & 200 & 200 & 200 & 200 & 200 & 200 & 200 \\
\hline
\end{tabular}




\section{Friability}

Ten tablets were weighed and placed in a standard Roche friabilator (FT2, Sotax, Switzerland). The friabilator was operated at 25 rpm for $4 \mathrm{~min}$, and the friability was then calculated as the percent loss in weight after the run [13].

\section{In vitro disintegration test}

The in vitro disintegration test was performed according to the European Pharmacopoeia at 35 ${ }^{\circ} \mathrm{C}$ in $900 \mathrm{~mL}$ of distilled water. One tablet was placed in each of the six tubes of the apparatus containing distilled water. A disk was added to each tube. The time required for the complete disintegration of the tablet until no mass remaining in the tube was measured. The disintegration time of three tablets in a single batch was determined, and the mean value and standard deviation was calculated [14].

\section{Evaluation of experimental data with neural networks}

In this study, the FormRules V3.32 (Intelligensys Ltd., UK) and INForm V.5 programs were used. FormRules V3.32 is a data-mining software package using NFL as its basis. INForm is called a neural network software package; however, it encompasses not only neural networks with a back-propagation algorithm type but also genetic algorithms, fuzzy logic, statistical techniques and visualisation capabilities. While the task of establishing a central model is undertaken by the neural network element, the genetic algorithm, fuzzy logic and pre-trained models are used for optimisation of formulation [2].

Both software programs include ANOVA (variance analysis) statistics for the evaluation of the models. The train set r-squared and computed f-ratio studied. A higher train set $r$ squared value demonstrates that more models have captured variation in the data; a value greater than $70 \%$, supported by an f-ratio higher than 4 , is considered appropriate. ANOVA rsquared values are demonstrated on a coloured background. If the values are r-squared $\geq 70 \%$ and $\leq 99.9 \%$, a green colour shows that the condition is good; for values from 50 to $70 \%$, yellow indicates the need for caution; and if $r$ squared $\leq 50 \%$, a red colour shows that the model is not good. If $r$-squared $\geq 99.9 \%$, the colour will still be red because the model is overtrained beyond the necessary point [2]. In our study, as mentioned before in study design section, disintegrant type and amount, (CQAs) and compression pressure (CPP) were considered the inputs, and hardness, friability and disintegration time (QTPP) were the outputs.

\section{Evaluation of data using Neuro-Fuzzy Logic}

The experimental data obtained from the analysis of ODT tablets were entered into the NFL program; disintegrant type, disintegrant amount, Avicel amount and compression pressure were considered the inputs; hardness, friability and disintegration time were considered the outputs. The disintegrant type was coded as 0 for Ludiflash $\AA$ and 1 for Parteck $\AA$. In neural fuzzy logic, cross-validation (CV), minimum descriptor length (MDL), structural risk minimizing (SRM), leave one out cross-validation (LOOCV) and Bayesian information criterion (BIC) models were evaluated for data training. SRM was chosen as the training model because it produced the maximum train set $r$-squared and minimum mean square error (MSE) values. After training the program, the relations between ingredients and properties were defined with submodels using NFL. The compliance of the model was expected according to the $r$-squared and $f$ ratio values that resulted from the ANOVA statistics.

\section{Optimisation with Gene Expression Programming}

Experimental data were analysed with the GEP to determine how to identify the optimum properties to achieve the optimum desired properties of the product formulation and/or treatment variables. In the GEP program, disintegrant type, disintegrant amount, Avicel amount and compression pressure were considered the inputs; hardness, friability and disintegration time were considered the outputs. Fifteen percent of the complete data (2 formulations) were used as test data to prevent overtraining, and 16 formulations were used for model training. The test data selection was made using the "Smart Selection" method. The criterion for judging the models, fitness type were selected as Mean Square Error (MSE). After the training was complete and the model was built, the optimisation process was pursued. The optimised formulation was determined by GEP. To find the formulation with the closest match to the optimised formulation, the best match feature of the program was used.

\section{RESULTS}

\section{Pre-compression characteristics}

For the flow characteristic of a powder mixture to be considered good, the Hausner ratio should be 
less than 1.25 [15]. As shown in Table 2, the Hausner ratio for all the formulations was $\leq 1.25$, and the flow properties of all the formulations were considered good. Regarding Carr's index, the literature indicates that ratios of $5-15 \%$ indicate excellent compressibility, $18-21 \%$ indicate medium compressibility, and 23 - $35 \%$ indicate poor compressibility. Among the formulations prepared, F3, F6, F9 exhibited medium compressibility (20\%) and F10, F13, F16 had good compressibility (15\%); the others had excellent compressibility (8 - $11 \%$ ) (Table 2). Consequently, the overall flow characteristics of the prepared formulations were found suitable for an ODT form in terms of compressibility.

\section{Post-compression characteristics}

The results of the weight deviation, hardness, disintegration time and friability tests are presented in Table 3 . The disintegration time varied depending on the formulation components and the compression force, although all the formulations except F7 complied with the European Pharmacopoeia limits. The hardness values and compression forces were directly proportional, as expected, and they also differed regarding other formulation variables. The F7 formulation had the highest hardness value and the longest disintegration time. All the friability values were below $1 \%$, and they were consistent. It was observed that an increase in friability was inversely proportional to the disintegrant amount.

\section{Evaluation of experimental data using Neuro- Fuzzy Logic}

The sub-models and $r$-squared values obtained from NFL are shown in Table 4.

Table 2: Flow characteristics of powder blends

\begin{tabular}{lllllll}
\hline Parameter & \multicolumn{7}{c}{ Powder blend } \\
\cline { 2 - 6 } & F1/F4/F7 & F2/F5/F8 & F3/F6/F9 & F10/F13/F16 & F11/F14/F17 & F12/F15/F18 \\
\hline Bulk density & 0.4618 & 0.5084 & 0.4814 & 0.4863 & 0.5472 & 0.61 \\
Tapped density & 0.5247 & 0.5772 & 0.6017 & 0.5611 & 0.608 & 0.6654 \\
Hausner ratio & 1.13 & 1.1363 & 1.25 & 1.1538 & 1.11 & 1.09 \\
Carr's index & 11.98 & 11.919 & 20 & 15.38 & 10 & 8.32 \\
\hline
\end{tabular}

Table 3: ODT tablet characteristics

\begin{tabular}{lllll}
\hline Code & Disintegration time $(\mathbf{s})$ & Hardness $(\mathbf{K p})$ & Friability $(\mathbf{F}, \%)$ & Weight variation $(\mathbf{g})$ \\
\hline F1 & 80 & 8.10 & 0.19 & $0.1994 \pm 0.0025$ \\
F2 & 45 & 5.70 & 0.38 & $0.1995 \pm 0.0022$ \\
F3 & 14 & 4.70 & 0.91 & $0.19819 \pm 0.007$ \\
F4 & 111 & 23.03 & 0.01 & $0.19948 \pm 0.0026$ \\
F5 & 68 & 17.76 & 0.04 & $0.19950 \pm 0.0022$ \\
F6 & 24 & 13.43 & 0.06 & $0.1982 \pm 0.0072$ \\
F7 & 201 & 32.06 & 0.01 & $0.19986 \pm 0.0024$ \\
F8 & 154 & 24.60 & 0.06 & $0.19968 \pm 0.0022$ \\
F9 & 117 & 20.96 & 0.09 & $0.19804 \pm 0.0072$ \\
F10 & 25 & 6.30 & 0.20 & $0.20064 \pm 0.0023$ \\
F11 & 10 & 5.73 & 0.20 & $0.19898 \pm 0.0022$ \\
F12 & 10 & 4.46 & 0.52 & $0.2017 \pm 0.00218$ \\
F13 & 50 & 20.33 & 0.03 & $0.2021 \pm 0.00231$ \\
F14 & 29 & 17.90 & 0.03 & $0.19898 \pm 0.0010$ \\
F15 & 23 & 14.90 & 0.05 & $0.2010 \pm 0.00310$ \\
F16 & 165 & 28.26 & 0.01 & $0.19218 \pm 0.0117$ \\
F17 & 90 & 27.0 & 0.05 & $0.2002 \pm 0.00268$ \\
F18 & 76 & 27.63 & 0.33 & $0.19624 \pm 0.0160$ \\
\hline
\end{tabular}


Table 4: Neuro-fuzzy Models - Relations between ingredients and properties

\begin{tabular}{|c|c|c|}
\hline Neuro-fuzzy Models & & \\
\hline - Rules for property Disintegration Tim & & \\
\hline & $\begin{array}{l}\text { Train Set r-squared (\%) } \\
\text { Computed f- ratio } \\
\text { MSE }\end{array}$ & $\begin{array}{l}93.73 \\
359.06 \\
0.005\end{array}$ \\
\hline SubModel:1 & & \\
\hline IF Compression pressure (psi) is LOW & THEN Disintegration time(s) is & $\operatorname{LOW}(1.00)^{*}$ \\
\hline IF Compression pressure (psi) is MID & THEN Disintegration time(s) is & $\operatorname{LOW}(1.00)^{*}$ \\
\hline IF Compression pressure (psi) is HIGH & THEN Disintegration time(s) is & $\mathrm{HIGH}(1.00)^{*}$ \\
\hline Sub Model:2 & & \\
\hline IF Disintegrant amount is LOW & THEN Disintegration time(s) is & $\mathrm{HIGH}(0.85)^{*}$ \\
\hline IF Disintegrant amount is $\mathrm{HIGH}$ & THEN Disintegration time(s) is & $\operatorname{LOW}(1.00)^{*}$ \\
\hline Sub Model:3 & & \\
\hline IF Disintegrant type is LOW & THEN Disintegration time(s) is & $\mathrm{HIGH}(0.66)^{*}$ \\
\hline IF Disintegrant type is $\mathrm{HIGH}$ & THEN Disintegration time(s) is & $\operatorname{LOW}(0.93)^{*}$ \\
\hline --- Rules for property Hardness (Kp) - & & \\
\hline & $\begin{array}{l}\text { Train Set } r \text {-squared (\%) } \\
\text { Computed } f \text {-ratio } \\
\text { MSE }\end{array}$ & $\begin{array}{l}98.66 \\
40.03 \\
0.0028\end{array}$ \\
\hline SubModel:1 & & \\
\hline IF Disintegrant type is LOW & THEN Hardness $(\mathrm{Kp})$ is & $\operatorname{LOW}(1.00)^{*}$ \\
\hline IF Disintegrant type is HIGH & THEN Hardness $(\mathrm{Kp})$ is & $\mathrm{HIGH}(1.00)^{*}$ \\
\hline SubModel:2 & & \\
\hline IF Compression pressure (psi) is LOW & THEN Hardness $(\mathrm{Kp})$ is & $\operatorname{LOW}(1.00)^{*}$ \\
\hline IF Compression pressure (psi) is $\mathrm{HIGH}$ & THEN Hardness $(\mathrm{Kp})$ is & $\mathrm{HIGH}(1.00)^{*}$ \\
\hline SubModel:3 & & \\
\hline IF Avicel (mg) is LOW & THEN Hardness $(\mathrm{Kp})$ is & $\mathrm{HIGH}\left(0.68^{\star}\right)$ \\
\hline IF Avicel (mg) is $\mathrm{HIGH}$ & THEN Hardness $(\mathrm{Kp})$ is & $\operatorname{LOW}(0.68)^{*}$ \\
\hline -- Rules for property Friability (F) --- & & \\
\hline & $\begin{array}{l}\text { Train Set r-squared } \\
\text { Computed f-ratio } \\
\text { MSE }\end{array}$ & $\begin{array}{l}79.4609 \\
125.734 \\
0.0178 \\
\end{array}$ \\
\hline SubModel:1 & & \\
\hline IF Disintegrant type is LOW & THEN Friability $(F)$ is & $\operatorname{LOW}(1.00)^{*}$ \\
\hline IF Disintegrant type is HIGH & THEN Friability $(F)$ is & $\mathrm{HIGH}(1.00)^{*}$ \\
\hline SubModel:2 & & \\
\hline IF Disintegrant amount is LOW & THEN Friability $(F)$ is & $\operatorname{LOW}(0.87)^{*}$ \\
\hline IF Disintegrant amount is $\mathrm{HIGH}$ & THEN Friability $(F)$ is & $\mathrm{HIGH}(0.91)^{*}$ \\
\hline SubModel:3 & & \\
\hline IF Compression pressure (psi) is LOW & THEN Friability $(F)$ is & $\mathrm{HIGH}(0.78)^{*}$ \\
\hline IF Compression pressure (psi) is $\mathrm{HIGH}$ & THEN Friability $(F)$ is & $\operatorname{LOW}(0.82)^{*}$ \\
\hline
\end{tabular}

* The confidence level $(0-1)$ for the sub-models

According to the sub-models, the disintegration time was affected by three input variables which are compression pressure, disintegrant concentration and disintegrant type. Using these variables, relationships, which were modelled, demonstrated that the disintegration time 
decreased with an increase in the related disintegrant amount, the disintegration time was shorter when Parteck ${ }^{\circledR}$ was used, and the disintegration time increased when the compression force was increased as seen from the confidence level $(0-1)$ for the sub-model (Table 4).

According to the sub-models, low hardness would be obtained if the Ludiflash $\AA$ as disintegrant were used, and high hardness would be obtained if Parteck $\AA$ were used. It was indicated that the hardness increased with an increase in compression value, and low hardness was obtained when the Avicel amount was high (Table 4).

According to the sub-models of the friability it was low if the Ludiflash® was used and high if

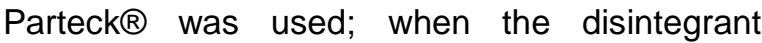
amount increased, the friability also increased; and if the compression force were $1000 \mathrm{psi}, \mathrm{a}$ lower friability would be observed (Table 4).

The consistency of the output variables measured with the predicted values obtained from the model was demonstrated by a scatter plot and a regression fit line and the correlation coefficients were 0.9373 for disintegration time, 0.9624 for hardness and 0.7946 for friability. The confidence levels $\left(^{*}\right)$ were found to be $0.66-1.00$ for all the sub-models. The program listed experimental formulations based on the proximity ratios with the model it built. The proximity ratios of the formulations to the model were classified by the neuro fuzzy program. According to this classification, the three formulations closest to the model were F3, with a $99.4956 \%$ proximity; F11, with a percentage of $99.3844 \%$ proximity; and F12, with a percentage of $99.2954 \%$ proximity. It was determined that 9 of the formulations built clinically and by program showed compliance levels greater than $90 \%$ and very close to the model. According to the NFL program, the most suitable formulations were F3, F11 and F12.

\section{Optimisation with Gene Expression Programming}

Using the experimental data, a model with GEP was also developed, and an optimised formula was sought, validation was performed to prevent overtraining. In our model, $15 \%$ of the formulations were used as the test data. In the program, it is possible to perform manual, random, import test data and smart selection. However, we concluded, based on our experiences that the smart selection was preferable based on its superior separation of the test data. The program was trained with the experimental data, and the suitability of the model was assumed based on the r-squared and f-ratio values from the ANOVA statistics. In the model established by GEP, the training results of disintegration time (s): train set $r$-squared value was $97.134 \%$, computed f-ratio was 19.0443, and the MSE was 0.004328; the training results of hardness $(\mathrm{Kp})$ : train set $r$-squared value was $99.108 \%$, computed f-ratio was 61.3377 , and the MSE was 0.002854 ; the training results of friability $(F)$ : train set $r$-squared value was 96.68 $\%$, computed f-ratio was 16.8468 , and the MSE was 0.004352 .

The consistency of the output variables measured with the predicted values obtained from the model was demonstrated by a scatter plot and regression fit line and the correlation coefficients were 0.9632 for disintegration time, 0.9967 for hardness and 0.9727 for friability. The GEP listed experimental formulations based on the proximity ratios with the model it built. According to this classification, the three formulations closest to the model were F12, with a $94.6144 \%$ proximity; F11, with a $94.3367 \%$ proximity; and F3, with a $92.7308 \%$ proximity. It was determined that 3 of the formulations built by experiment and by program showed compliance levels greater than $90 \%$ and very close to the model. The variables demonstrated to be correlated by the GEP analysis are shown as 3D graphs in Figure 1. The friability decreased when the compression pressure was increased and the disintegrant amount was decreased. Harder tablets were obtained with Parteck $\AA$ when compared to Ludiflash $B$ and a decrease in the amount of disintegrant increased the friability. If the compression pressure was increased, the hardness also increased.

Based on the evaluation of the GEP data, an ODT formulation was recommended. The suggested "optimised formulation" contained 4 mg Ondansetron, 21.30 mg Parteck®, and 119 mg Avicel and fabricated with a compression force of 515 psi. The program also provided "outputs" for the formula that it suggested. Accordingly, the predicted formulation properties of the optimised formula were $4.85 \mathrm{~s}$ for disintegration time, $18.2 \mathrm{Kp}$ for hardness and $0.023 \%$ for friability. Subsequently, the optimised formula was tested in the laboratory, and the obtained results were suitable to the values predicted by the program for the optimised formula. 


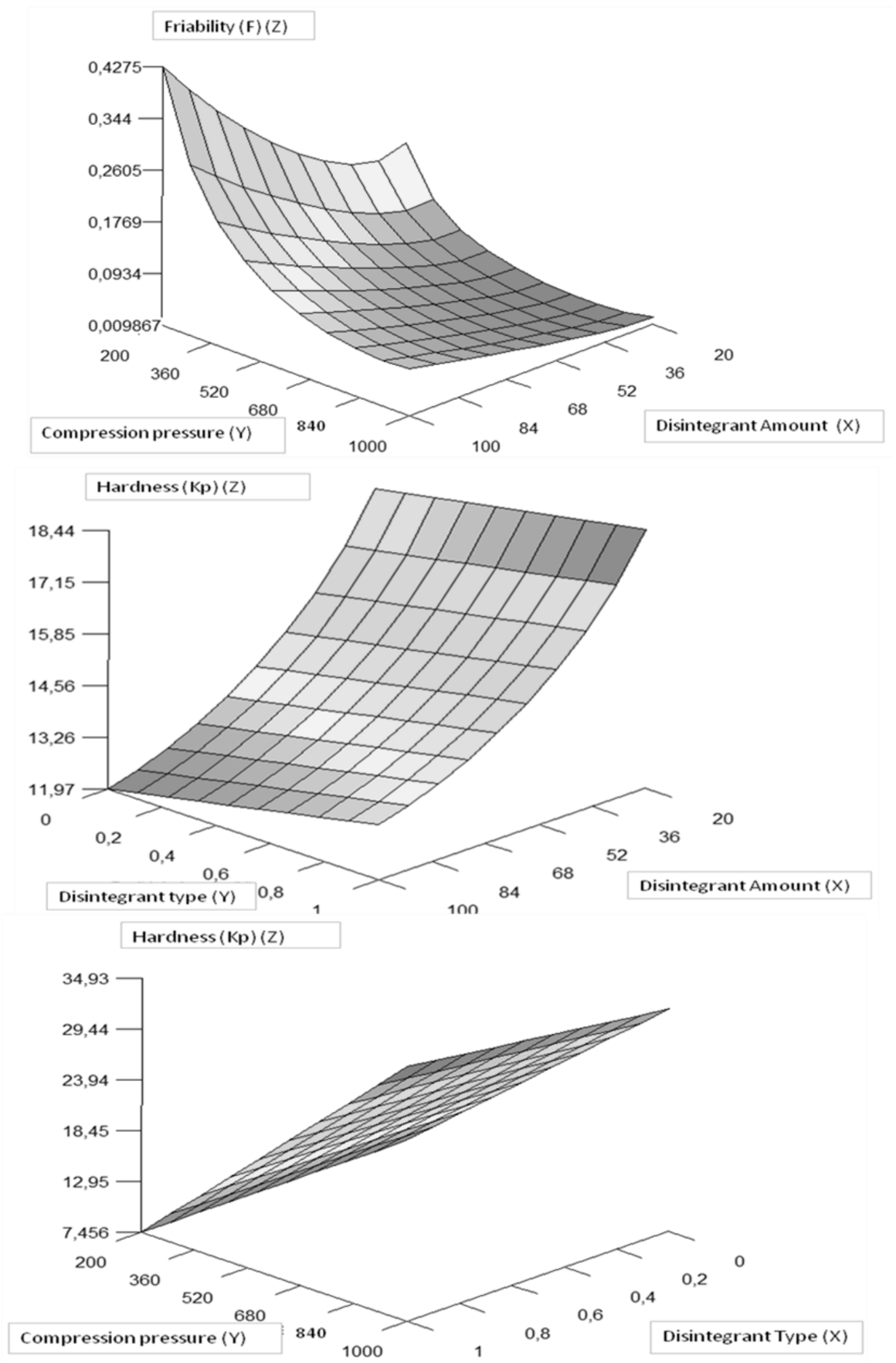

Figure 1: Relationship between input variables and output variables

The GEP model also provided us information concerning which formulation best fit the optimised formula that it proposed. F12 was found to be the most similar to the optimised formulation, with a $94.6144 \%$ match by the GEP model; this formulation also showed high compliance with the neuro-fuzzy model (99.2954 $\%)$. 


\section{DISCUSSION}

ANN programs have been used to develop pharmaceutical formulations. Shao et al [16] employed neuro-fuzzy technologies to compare NNs against NFL techniques. They concluded that the models developed using NFL methods were almost as good as the models that employed neural networks. Shao et al [17] also investigated the integration of secret data into multiple formulations using NFL and demonstrated that more data could be accessed using NFL than when classical methods were employed. Kesavan and Peck [18] modelled the tablet formulation of caffeine to examine the relationships among the formulation (diluent, binder and their concentrations) and processing variables (granulator type and lubricant addition method) and the granule and tablet properties (fragility, crushing strength and dissolution time). They demonstrated that NN worked better than the usual statistical methods. Lindberg and Colbourn [19] utilized NN, GAs and NFL to analyse historical data derived from different immediate-release formulations. According to their results, established models were very efficient in the manufacture of tablets with desired properties.

As indicated in the Q8 guideline of the $\mathrm{ICH}$, the literature can provide the knowledge space for the target quality product profile that we should determine in the formulation selection [20]. Additionally, working with neural networks has helped to improve our knowledge of developing ODT formulations. NFL has been especially useful for determining the interactions between the formulation and the analysed process parameters and target product properties that we could not observe or conclude from the experimental data. On the other hand, with GEP, an extremely easy selection of the desired formulation and the analysed process parameters from laboratory studies have guided our research, and the proper OND containing ODT formulation has been easily and successfully formulated.

By using this program, optimized formula providing critical quality attributes is obtained by training with only 18 formulations and also we easily determined which disintegrant is the most proper for our formulation. GEP model recommended a formulation that we did not evaluate before which meets the requirements. When considered from this perspective, neural networks has a function for reducing the time and cost for the industry.
The simultaneous use of these programs, especially in studies prior to scale-up, either for decreasing the amount of experimental data or for occasionally obtaining results that cannot be achieved by experimental studies, has been quite useful with respect to obtaining successful results and understanding formulation and process interactions. Although such studies are encountered in the literature $[1,2,21,22]$, the convenience of the application on ODT has contributed to the reliability of the studies.

\section{CONCLUSION}

Consequently, this study, which was conducted to develop ODTs containing the model drug OND, demonstrated that an ANN approach can be used to prepare formulations easily and successfully and that the use of this approach can be beneficial in terms of raw materials, time and cost.

\section{REFERENCES}

1. Aksu B, Paradkar A, Matas MD, Ozer O, Guneri T, York P. Quality by Design approach: Application of artificial intelligence techniques of tablets manufactured by direct compression. AAPS Pharm Sci Tech 2012; 13(4): 1138-1146.

2. Aksu B. Innovative Pharmaceutical Manufacturing Applications On The Manufacturing Process For The Tablets Containing Ramipril As Drug Substance. Ege University. Faculty of Pharmacy, Ph Thesis, Izmir, 2010.

3. Aksu B, Paradkar A, Matas MD, Ozer O, Guneri T, York $P$. A quality by design approach using artificial intelligence techniques to control the critical quality attributes of ramipril tablets manufactured by wet granulation. Pharm Dev Technol 2013; 18(1): 236 245.

4. Azamathulla HMD, Haque AAM. Prediction of Scour Depth at Culvert Outlets Using Gene-Expression Programming. Int J Innov Comput I 2012; 8-7(B): 5045-5054.

5. Velmurugan $S$, Vinushitha $S$. Oral Disintegrating Tablets: An Overview. Int J Chem Pharm Sci 2010; 1(2): 1-12.

6. Olmez SS, Vural I, Sahin S, Ertugrul A, Capan Y. Orally disintegrating Tablets II: In Vitro and In Vivo Evaluations. Hacettepe University Journal of the Faculty of Pharmacy 2011; 31(1): 59-70.

7. Thakur RR, Narwal S. Formulation and Evaluation of Orally Disintegrating Tablet of Niacinamide. Res $J$ Pharm Biol Chem Sci 2012; 3(3): 292-302.

8. Bhasin RK, Bhasin $N$, Ghosh PK. Advances in Formulation of Orally Disintegrating Dosage Forms: A Review Article. Indo Global J Pharm Sci 2011; 1(4): 328-353. 
9. Pfister WR, Ghosh TK. Orally Disintegrating Tablets Products, Technologies, and Development Issues. Pharm Technol 2005; 29(10): 138-150.

10. Gregory RE, Ettinger DS. 5-HT3 receptor antagonists for the prevention of chemotherapy-induced nausea and vomiting. A comparison of their pharmacology and clinical efficacy. Drugs 1998; 55(2): 173-189.

11. Devi M, Naga J, Reddy S. Design and characterization of melt-in-mouth tablets of metoprolol tartarate. Int $J$ Pharm Life Sci 2013; 4(4): 2608-2614.

12. Narmada GY, Mohini K, Prakash Rao B, Gowrinath DXP, Kumar KS. Formulation, Evaluation and Optimization of Fast Dissolving Tablets Containing Amlodipine Besylate by Sublimation Method. Ars Pharm 2009; 50(3): 129-144.

13. Divyeshkumar NV, Maulik PM, Ujjwal JT, Jaykishan MP. Design, development and characterization of orally disintegrating tablet of prochlorperazine maleate. $J$ Chem Pharm Res 2010; 2(5): 307-312.

14. European pharmacopoeia. Pharmaceutical technical procedures: Disintegration of tablets and capsules, ed 7, EDQM, Council of Europe, Strasbourg, France, 2011; 254.

15. Bhowmik D, Chiranjib B, Krishnakanth, Pankaj, Chandira RM. Fast Dissolving Tablet: An Overview. J Chem Pharm Res 2009; 1(1): 163-177.

16. Shao $Q$, Rowe $R C$, York $P$. Comparison of neurofuzzy logic and decision trees in discovering knowledge from experimental data of an immediate release tablet formulation. Eur J Pharm Sci 2007; 31: 129136.

17. Shao $Q$, Rowe RC, York P. Data mining of fractured experimental data using neurofuzzy logic-discovering and integrating knowledge hidden in multiple formulation databases for a fluid-bed granulation process. J Pharm Sci 2008; 97: 2091-2101.

18. Kesavan JG, Peck GE. Pharmaceutical granulation and tablet formulation using neural networks. Pharm Dev Technol 1996; 1: 391- 404.

19. Colbourn E., Lindberg N. Use of Artificial Neural Networks and Genetic Algorithms - Experiences from a Tablet Formulation. Pharm Tech Eur 2004; 16(5): 35-39

20. ICH Harmonised Tripartite Guideline, Pharmaceutical development Q8(R2). International Conference on Harmonisation of Technical Requirements for Registration of Pharmaceuticals for Human Use 2009.

21. Aksu B, De Matas M, Cevher E, Ozsoy Y, Guneri T, York P. Quality by Design Approach for Tablet Formulations Containing Spray Coated Ramipril by Using Artificial Intelligence Techniques. Inter J Drug Del 2012; 4(1): 59-69.

22. Mesut B, Aksu B, Ozsoy Y. Design of Sustained Release Tablet Formulations of Alfuzosin $\mathrm{HCl}$ by means of Neuro-Fuzzy Logic. Lat Am J Pharm 2013; 32(9): 1288-1297. 